\section{Microscopy} Coming Events

2013

Neuroscience

November 9-13, 2013

San Diego, CA

www.sfn.org/am2013

2013 MRS Fall Meeting

December 1-6, 2013

Boston, MA

www.mrs.org/fall2013

\section{ASCB Annual Meeting}

December 14-18, 2013

New Orleans, LA

www.ascb.org/meeting

\section{4}

Quantitative Biolmaging Conference January 9-11, 2014

University of New Mexico, Albuquerque, NM www.quantitativebioimaging.com

Human Amyloid Imaging Conference January 15-17, 2014

Miami, FL

www.worldeventsforum.com/hai

ACMM23 and ICONN 2104

February 2-6, 2014

Adelaide, Australia

www.aomevents.com/ACMMICONN

Pittcon '14

March 2-7, 2014

Chicago, IL

www.pittcon.org

Microscopy \& Microanalysis 2014

August 3-7, 2014

Hartford, CT

www.microscopy.org

\section{5}

Microscopy \& Microanalysis 2015

August 2-6, 2015

Portland, OR

www.microscopy.org

\section{6}

Microscopy \& Microanalysis 2016 July 24-28, 2016

Columbus, $\mathrm{OH}$

www.microscopy.org

\section{7}

Microscopy \& Microanalysis 2017

July 23-27, 2017

St. Louis, MO

www.microscopy.org

\section{8}

Microscopy \& Microanalysis 2018 August 5-9, 2018

Baltimore, MD

www.microscopy.org

More Meetings and Courses

Check the complete calendar near the back of this magazine.

\title{
Geared Up for Jumping!
}

\author{
Stephen W. Carmichael \\ Mayo Clinic, Rochester, MN 55905 \\ carmichael.stephen@mayo.edu
}

Gears are rarely found in animals, and when they are, they have never been reported to intermesh and rotate functionally as mechanical gears. Until now, that is. Malcolm Burrows and Gregory Sutton used microscopes to locate gears in the planthopper Issus coleoptratus and made high-speed videos to record the gears in action [1]. This flightless insect goes through about five nymphal stages before becoming an adult. The nymphs, but not adults, have gears to synchronize jumping movements in their hind legs. The oldest nymphs are about $5 \mathrm{~mm}$ long, but they can jump about one meter! Apparently this is essential for avoiding predators and other natural behaviors.

Planthoppers are among the best jumping insects. The hind legs move counterrotationally in approximately the same near-horizontal plane beneath the body. With this arrangement, it is essential that the two legs be synchronized to avoid veering off to the left or right (referred to as spinning in the yaw plane). Using high-speed video microscopy (up to 30,000 frames per second), Burrows and Sutton found that take-off could occur within 2 milliseconds. The two propulsive hind legs started moving within 30 microseconds of each other. Such precise synchrony would be difficult to achieve with neural control that operates on a millisecond time scale. However, the left and right power-producing muscles are innervated by independent sets of two motor neurons each, and all four neurons are synchronized. Apparently the neural connection assists the synchronization of leg movements, but the gears ensure that the hind legs move together within microseconds of each other.

The proximal segment of each hind leg had a curved strip of gear teeth (Figure 1). The gear on one segment enmesh with a corresponding gear of the same size and

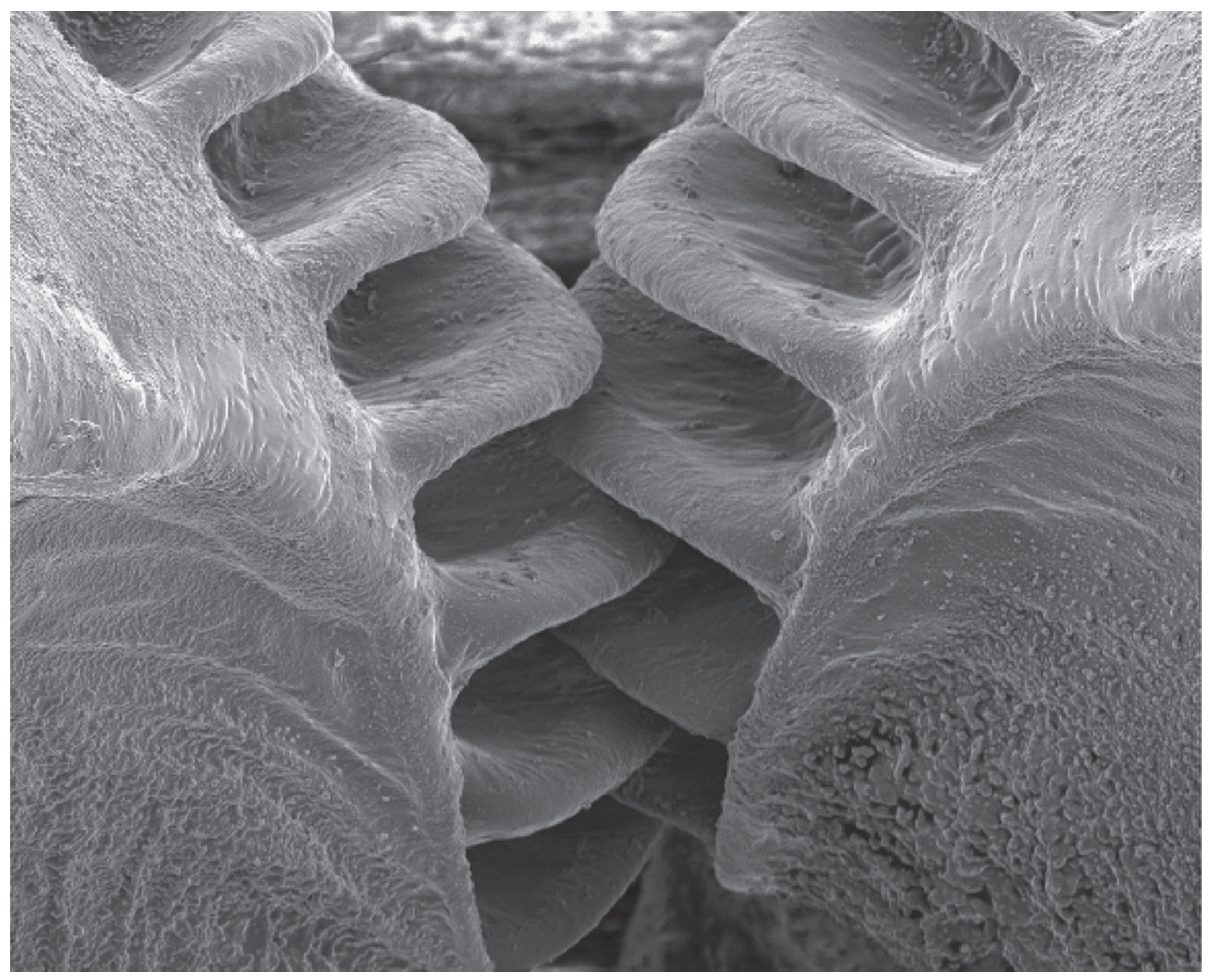

Figure 1: A scanning electron micrograph of gear teeth in the hind leg a planthopper nymph. Full width $=140 \mu \mathrm{m}$. 


\section{One image. Every detail.

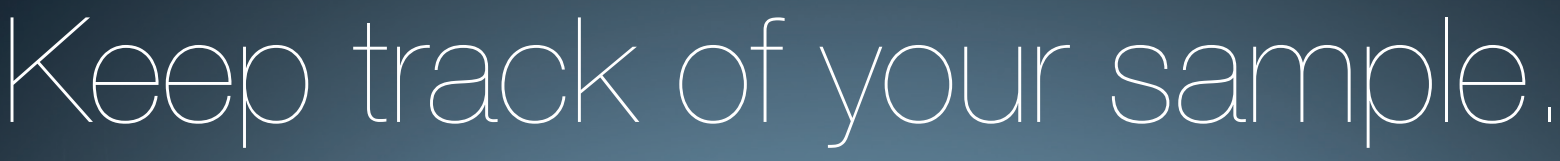

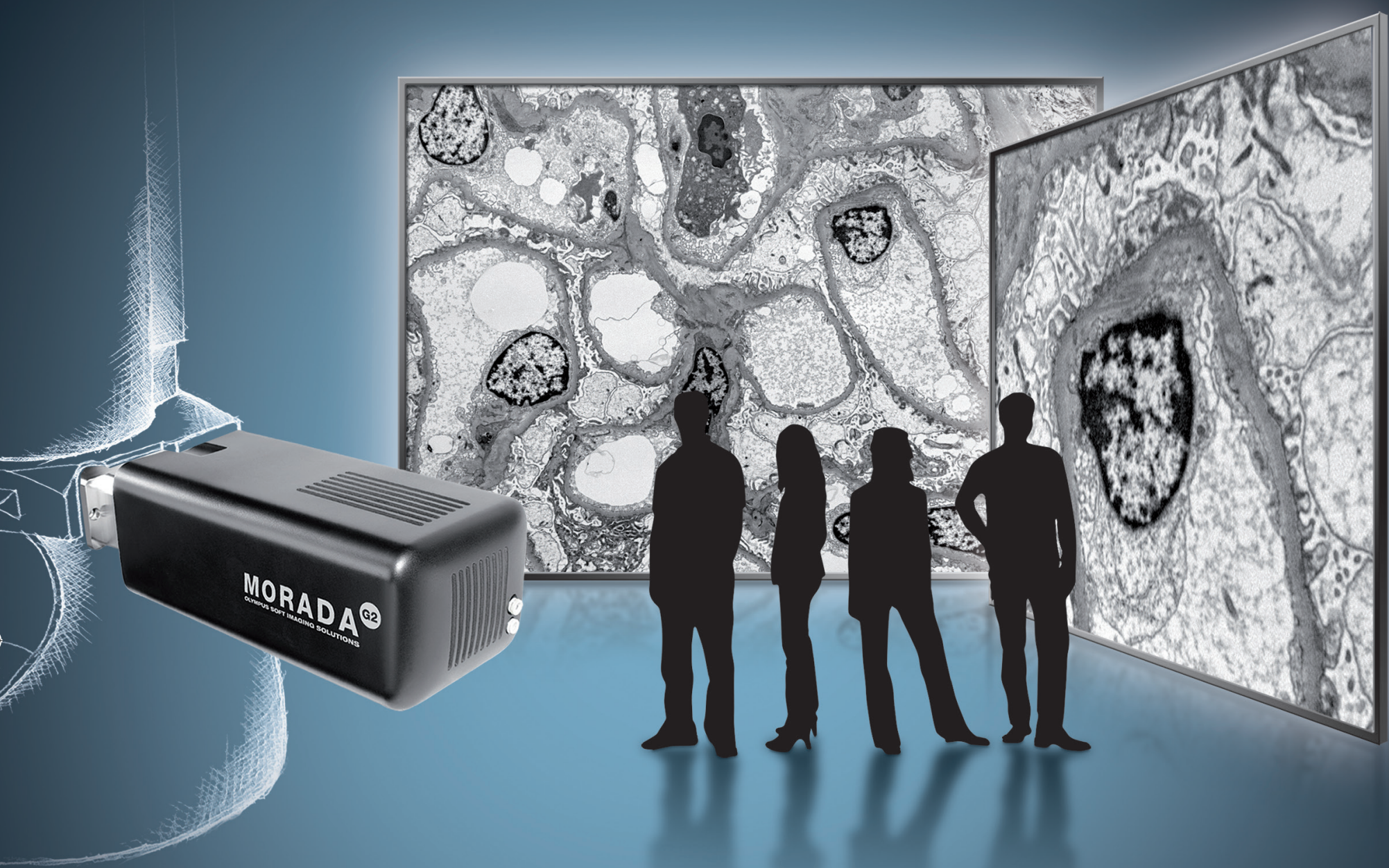

\section{Morada G2 - 11 Megapixel side-mounted TEM CCD camera}

Are you looking for a complete sample image? Are you interested in high resolution? Or do you need both - overview scans and image details? Whatever your requirements, the Morada G2 will be your camera of choice.

Experience a new method of TEM imaging and keep track of your sample. Survey your sample using an impressive field of view. Scan for interesting areas in real time. Zoom in on details instantly. Snap high-contrast, high-sensitivity and superior-resolution images. All these features and more make the Morada G2 perfect for every imaging task.

One image. Every detail. Just one camera. The Morada G2. Imaging solution for electron microscopy.

Based on opto-digital know-how. Designed by customer requirements.

For further information: info.osis@olympus-sis.com,

www.soft-imaging.net

\section{OLYMPUS}


shape on the other hind leg. Gears were not present on the front or middle legs.

Each gear strip was about $400 \mu \mathrm{m}$ long, contained 10 to 12 teeth, and had a radius of curvature of about $200 \mu \mathrm{m}$. Each gear tooth was about $9 \mu \mathrm{m}$ thick, $20 \mu \mathrm{m}$ tall, and separated from adjacent teeth by about $30 \mu \mathrm{m}$. The dark color of the teeth suggested that they are heavily sclerotized, which might be expected in a rugged mechanical gear. The shape of the teeth was asymmetrical, which would be appropriate if it only transmitted power while turning in one direction, as would be the case in jumping forward.

The gear teeth are lost during the final molt into adulthood. However, adults are better jumpers than nymphs. The gears are replaced by a high-performance system based on friction to achieve synchronization. If a gear tooth breaks in a nymph, it can be replaced at the next molt, but this is not possible after the final molt.

Burrows and Sutton have demonstrated that a mechanical arrangement, previously thought to be only in man-made machines, is present in nature to make it possible for planthoppers to jump straight!

\section{References}

[1] M Burrows and G Sutton, Science 341 (2013) 1254-56.

[2] The author gratefully acknowledges Dr. Malcolm Burrows for reviewing this article.
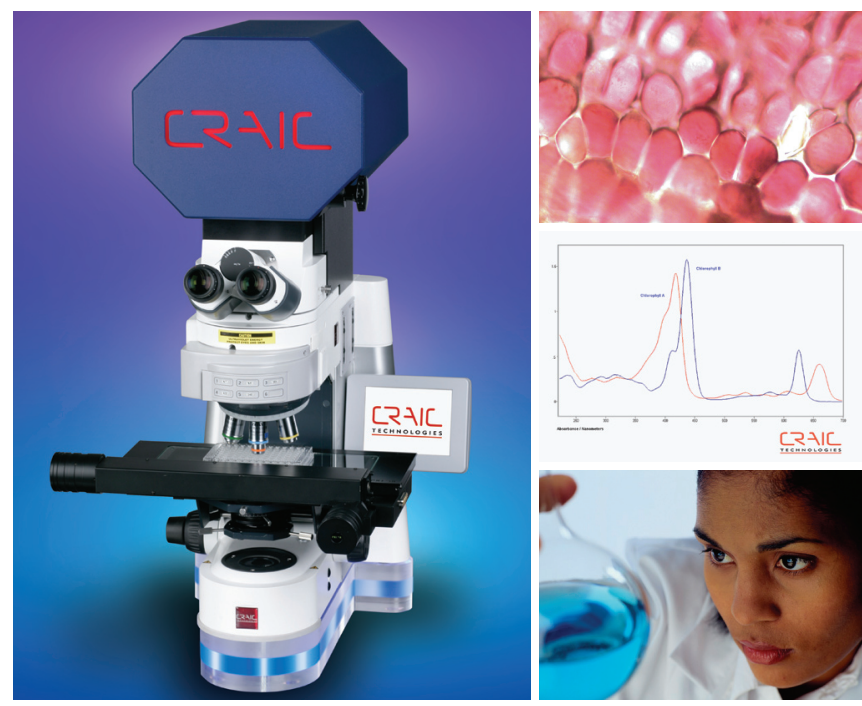

SPECTROSCOPY oF MICROSCOPIC SAMPLES

CRAIC Technologies UV-visible-NIR microscopes and microspectrophotometers are used for imaging and spectral analysis of sub-micron sized features with absorbance, reflectance, fluorescence, emission and polarized illumination. Capabilities include film thickness measurements, colorimetry and high resolution imaging in the UV, visible and NIR regions. Rapid \& accurate spectra \& images of microscopic samples: The Perfect Vision for Science ${ }^{T M}$.

For more information, call 877.UV.CRAIC or visit our website at www.microspectra.com @2011 CRAIC Technologies, Inc. San Dimas, California (USA).

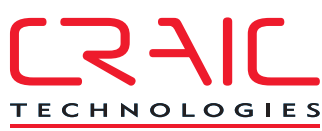

\section{EVACTRON ${ }^{\circledR}$ Zephyr $^{\mathrm{Tm}}$ De-Contaminators FAST, Large Volume, and Damage Free Cleaning}

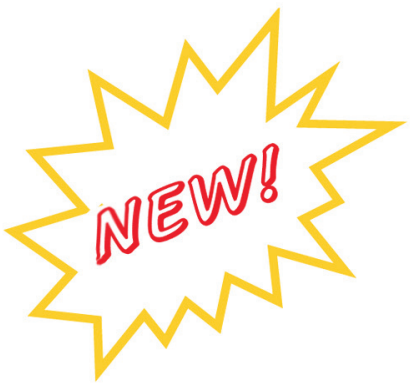

Evactron $^{\circledR}$

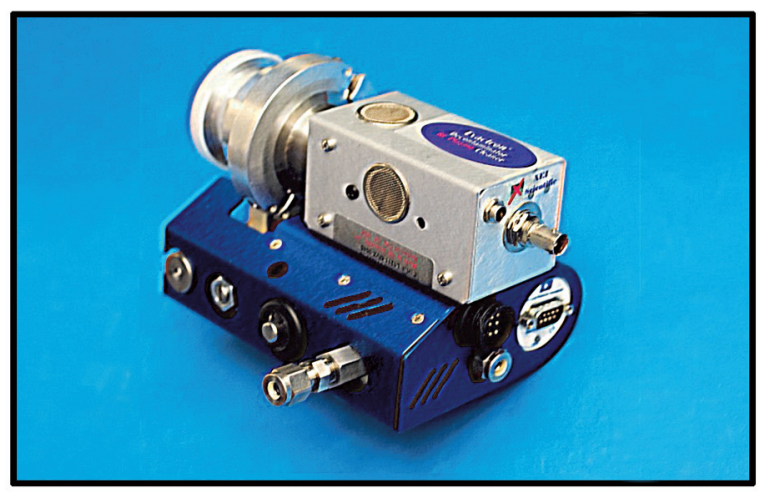

Zaps Dirt!

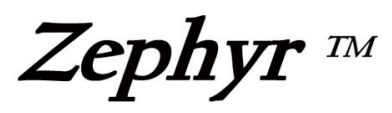

\section{plasma source does fast cleaning at full speed turbopump pressures.}

XEI

Scientific, Inc.
Zephyr upgrades for Evactron Models 25, 40 and 45 are available.

www.evactron.com | 1.650-369-0133 | sales@evactron.com 


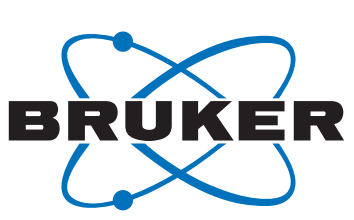

\section{5-in-1 fantasy: Giralope.}

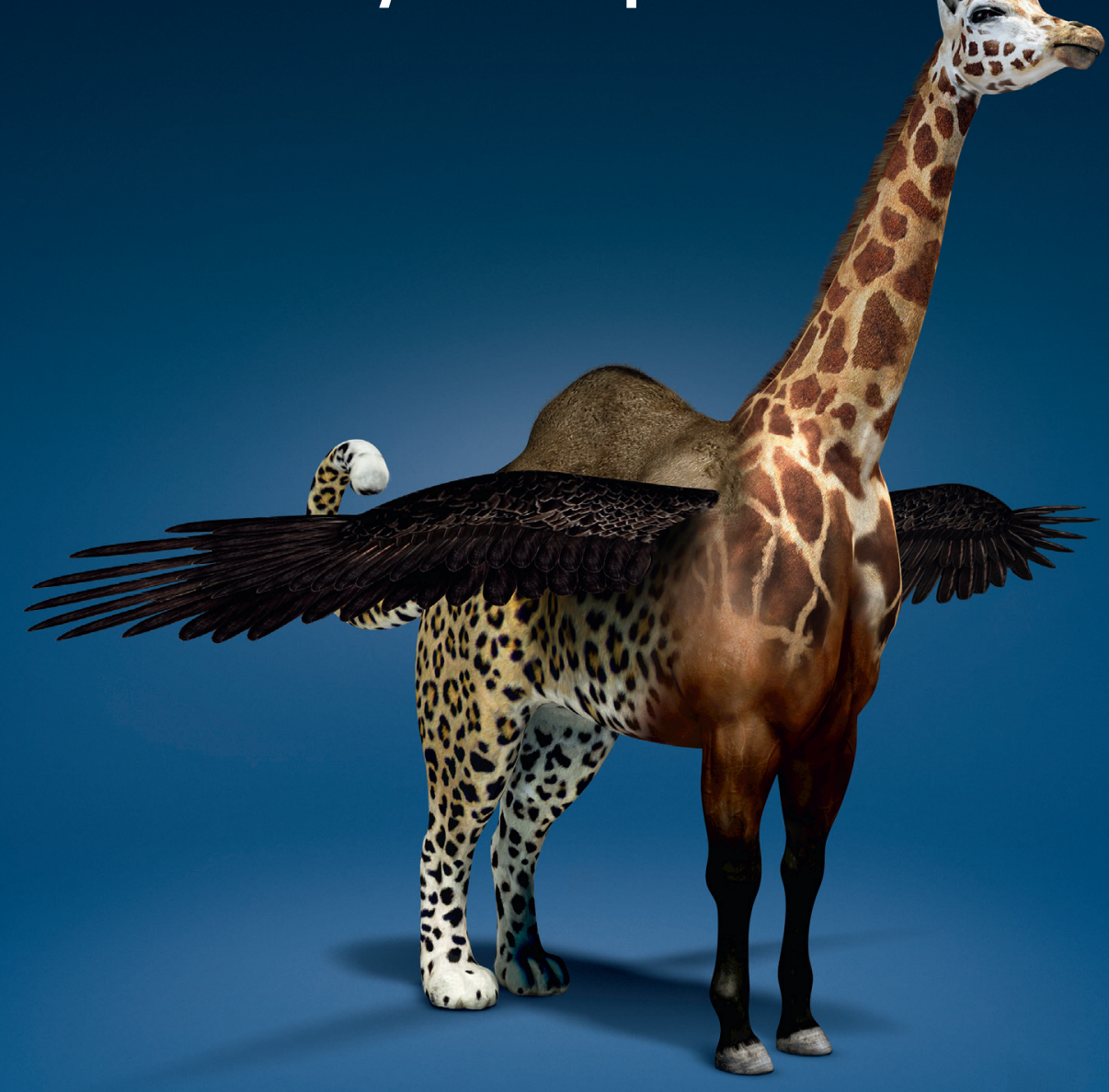

\section{5-on-1 reality: Bruker's range of analytical tools for SEM.}

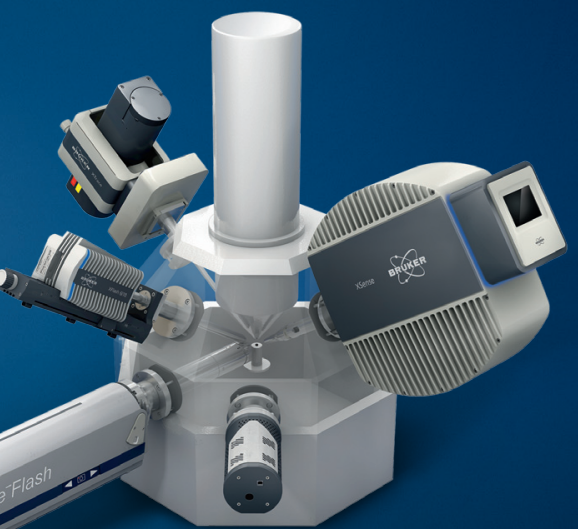

EDS, EBSD, WDS, Micro-XRF and Micro-CT - Bruker is the world's only manufacturer to offer five analysis methods for SEM. Plus, our new ESPRIT 2.0 software not only controls our QUANTAX EDS and QUANTAX CrystAlign EBSD but also, via its functional interface, our innovative new XSense WD spectrometer and XTrace micro-spot X-ray source. And because we know what you expect of us, we are already thinking about our next innovation. Someone has to be first.

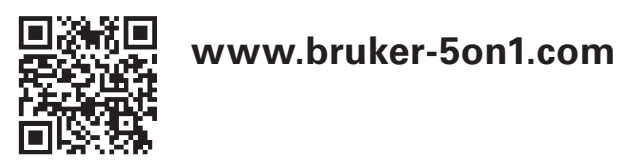

Innovation with Integrity 